\title{
“Las babas del diablo" e Blow Up: Uma análise da tradução intersemiótica na adaptação fílmica
}

\author{
Lia Leite Santos \\ Universidade Federal do Ceará
}

Resumo: Nosso trabalho tem o intuito de verificar a relação intersemiótica entre o conto "Las babas del diablo" (1959), do autor argentino Julio Cortázar, e o filme Blow Up (1966) do diretor e roteirista italiano Michelangelo Antonioni, através da análise do processo de tradução do texto literário para a adaptação fílmica. Para tanto, nos valeremos da Teoria Geral do Signo de extração pierceana e o comentário sobre tradução intersemiótica de Julio Plaza, considerando as três classes de signo, isto é, índice, ícone e símbolo, investindo nas propriedades analíticas dessa base de investigação; nos comentários sobre adaptação fílmica, cinema e literatura de Tânia Pellegrini; e na Teoria da Transcriação dos irmãos Augusto e Haroldo de Campos. Dedicamo-nos a levantar informações sobre dois aspectos do processo tradutório entre literatura e cinema, que correspondem ao efeito icônico do processo de reescrita e transcriação no filme Blow Up, e como as principais figuras da narrativa literária são apresentadas, observando o comportamento do signo no processo de deslocamento entre linguagens.

Palavras-chave: Tradução intersemiótica, adaptação fílmica, literatura, cinema

Abstract: Our work aims to verify the intersemiotic relationship between the short story "Las babas del diablo" (1959) by Argentine author Julio Cortázar and the film Blow Up (1966) by Italian director and writer Michelangelo Antonioni, through the analysis of the process of translation of the literary text for the film adaptation. We will use the General Theory of Piercean Sign and the intersemiotic translation of Julio Plaza, 
considering the three classes of sign, index, icon and symbol, investing in the analytical properties of this research base; the comments on film adaptation, cinema and literature by Tânia Pellegrini; and the Transcription Theory by brothers Augusto and Haroldo de Campos. We focus on two aspects of this translation process that correspond to the iconic effect of the process of rewriting and transcription in Blow $U p$, and how the main figures of the literary narrative are presented observing the behavior of the sign in the process of displacement between languages.

Keywords: Intersemiotic translation, film adaptation, literature, cinema

\section{A literatura de Cortázar e o cinema de Antonioni}

0 presente trabalho apresenta dois campos de linguagem de configurações distintas: o primeiro, o conto do escritor argentino "Las babas del diablo", de Julio Cortázar, publicado em Las Armas Secretas (1959), que se destaca como um de seus contos de maior relevo; e o segundo, o filme Blow Up (1966), dirigido e roteirizado por Michelangelo Antonioni, livremente inspirado no conto cortazariano. A partir desse corpus, faremos uma análise da perspectiva dos estudos da tradução, especificamente a tradução do aspecto intersemiótico do texto para tela, inserida no contexto crítico de aproximação entre cinema e literatura.

A princípio, apresentaremos o conto de Cortázar e o filme de Antonioni, para então expormos noções teóricas do pensamento pierceano, a respeito dos conceitos relacionados aos estudos intersemióticos, fundamentais para o nosso aparato analítico. Em seguida demonstraremos esses conceitos aplicados às cenas selecionadas da adaptação fílmica, com o intuito de observar como os signos, responsáveis pela construção de sentido do texto literário e do texto visual, se comportam no processo tradutório.

A partir da ideia de Tradução Icônica e Transcriação, lançaremos luz sobre como o conteúdo discursivo se apresenta após o deslocamento do signo da obra literária para a tradução cinematográfica. E através do trabalho de Pellegrini poderemos refletir sobre o diálogo e a aproximação entre literatura e cinema, ao pensarmos como as narrativas se desenvolvem nesses dois territórios de linguagem. 
"Las babas del diablo" transcorre em Paris e aborda a experiência do fotógrafo e tradutor franco-chileno Michel que, ao sair para um breve passeio no parque, fotografa um casal formado por uma mulher e um adolescente. A mulher, irritada pela ação invasiva do fotógrafo, protesta e exige que lhe seja entregue o rolo de negativos com as fotografias recém-captadas. Enquanto discutem, o rapaz que compunha o casal se retrai e foge da situação. Um quarto personagem surge para também reivindicar os negativos e após negarlhe tal objeto, Michel vai embora em posse de suas fotografias. Algum tempo depois, em casa, Michel revela as fotografias e ao contemplá-las percebe algo indefinido que lhe chama atenção. Faz uma ampliação da foto e em seguida uma ampliação da ampliação, o que o conduz à percepção de que aquelas eram as provas da iminência de um crime. A mulher não passava de uma isca para conduzir o jovem rapaz a um homem que o esperava para violentá-lo.

Além do plano narrativo, o texto de Cortázar possui também um plano discursivo metaliterário. Perspectiva e interpretação são temas suscitados como fatores que alteram o resultado da produção escrita, o que notoriamente intriga o narrador da obra. Como leremos no excerto a seguir, a narração em primeira pessoa introduz a discussão sobre como contar uma história, e as dificuldades de representar a realidade através de signos um problema comum tanto na arte da escrita, quanto nas artes visuais.

Nunca se sabrá cómo hay que contar esto. (...) Va a ser difícil porque nadie sabe bien quién es el que verdaderamente está contando, si soy yo o eso que ha ocurrido, o lo que estoy viendo (nubes, y a veces una paloma) si sencillamente cuento una verdad que es solamente mi verdad, y entonces no es la verdad. (Cortázar 1972: 79-80)1

Outra figura importante na construção discursiva é o processo de assujeitamento do personagem Michel, frente à busca da verdade e o ilusionismo dos fatos da vida. 0 protagonista, que num primeiro momento se mostra numa posição de superioridade nos jogos de poder centrados na posse das fotografias, em seguida fica suscetível às situações que estão fora de seu controle, perdendo a sua autonomia de sujeito da ação, o que se 
constitui como uma metáfora do próprio ato de narrar, cujas possibilidades de controle, o autor propõe que são limitadas.

O filme Blow Up se passa na Inglaterra e tem como personagem central Thomas, fotógrafo profissional que, bem como no conto, ao passear pelo parque se depara com um casal; no entanto, diferentemente de "Las babas del diablo", a mulher é bem mais jovem que o homem. Nesta adaptação o homem desaparece, enquanto a mulher discute com o fotógrafo, sem obter sucesso quanto às suas reivindicações para que lhe seja entregue o rolo de negativos. Ao revelar as fotografias, Thomas percebe que nas imagens a mulher olha constantemente para um arbusto, no qual, após as ampliações, é perceptível que há alguém com uma arma apontando para o homem. Ao retornar ao local, Thomas encontra o corpo do homem morto atrás dos arbustos, mas sem a câmera em mãos, não pode registrar o crime. No dia seguinte, ao voltar com a câmera, o corpo já não está.

Em Blow Up, há um prolongamento da estrutura fílmica pela inclusão de pequenas narrativas que abrangem a experiência de Michel como fotógrafo; a discussão com seu editor sobre a feitura de um livro; insinuações de envolvimento erótico com diversas mulheres; idas ao antiquário, entre outras. Para a nossa análise fez-se pertinente a seleção de cenas, tendo por critério a eleição daquelas que interseccionam mais diretamente a relação de tradução que desejamos trabalhar.

\section{Tradução Intersemiótica}

Analisando o diálogo entre o conto "Las babas del diablo" e a construção do metatexto que a narrativa erige, nota-se que há uma codificação da estrutura simbólica da obra cortaziana que endossa uma linguagem cifrada em sua poética. Assim, postulamos que na adaptação fílmica a tradução de simbologias para a linguagem cinematográfica fornece a chave para acessar o conteúdo de determinados signos presentes no conto. Para pensarmos esse processo de tradução, trabalharemos com as teorias pierceanas e as suas relações triádicas, para fazermos a identificação dos signos responsáveis pela construção de sentido no cerne textual literário e no texto visual.

Com base no pensamento de Charles Sanders Pierce (1839-1914), e sua contribuição 
para a Semiótica, pensaremos na definição de signo que visamos investigar, suas relações com os significantes e com objetos, e como os signos podem ser pensados nas relações triádicas pierceanas. Dessa perspectiva analítica, inicialmente, devemos compreender a linguagem como exercício lógico do pensamento que contém, pelo menos, três eixos: “a) as suas qualidades materiais que dão ao pensamento suas qualidades; b) aplicação denotativa ou conexão com o real; c) função representativa" (Plaza 2001: 21). Assim, Pierce define as distinções essenciais entre as qualidades materiais do signo, seu significante e seu objeto. Sobre a dinâmica signo-significante Pierce aponta que todo signo representa algo para alguém, isto é, cria na mente um objeto que, por sua vez, é seccionado em dois aspectos: Objeto Dinâmico, ligado ao objeto no mundo; Objeto Imediato, o objeto tal qual é representado. Pierce divide o signo em dez classes segmentadas em esquemas triádicos, mas em nosso estudo usaremos apenas as três classes articuladas na relação signo-objeto: são elas ícones, índices e símbolos.

Em termos gerais podemos dizer que o ícone guarda similaridades físicas com o seu objeto, portanto representa por semelhanças, como uma escultura ou um desenho. 0 índice opera pela contiguidade, isto é, a proximidade com o objeto que faz funcionar como uma indicação, tal a fumaça que indica que há um incêndio. E o símbolo é uma representação institucionalizada pela cultura em que está inserida, como a cor branca que pode representar a paz na cultura ocidental.

Essas três categorias se fazem importantes para pensarmos a Tradução Intersemiótica. A Tradução Icônica está pautada pela similaridade, e nisso consiste a demanda para "enfrentar o intraduzível do Objeto Imediato do original através de um signo transdutor" (Plaza 2001: 90). Julio Plaza comenta as duas subcategorias da tradução icônica cuja terminologia emprestada da física e da química ilustram as especificidades deste tipo de tradução: isomórfica e paramórfica. Sendo a primeira ligada à conservação das similaridades do modelo e da estrutura, enquanto a segunda mantém o modelo com "estrutura diferente e equivalente" (idem: 90). Na Tradução Indicial é mais presente a indicação da montagem como "referência por contiguidade" (idem: 92), valorizando mais a transposição por alusão do que um trabalho de criação. Para manter a contiguidade 
trabalham-se os aspectos metonímicos que estabelecem a ligação de referência entre o tradutor e o original. Plaza aponta que ao ocorrer esse movimento de metonímias, há um "deslizamento de significantes", que podem alterar a qualidade e os aspectos dos eventos (ibidem). Já a Tradução Simbólica conecta-se ao pensamento abstrato e à lógica de codificações convencionadas, como o Código Morse ou a linguagem binária.

Para o nosso trabalho, analisaremos "Las babas del diablo" em diálogo com Blow Up, utilizando as propriedades analíticas das traduções icônicas e indiciais. Especialmente a Tradução Icônica nos interessa por estar mais ligada ao recurso da transcriação, isto é, transformando o signo em sua nova linguagem. Como discutimos anteriormente, a tradução icônica é realizada pela efetivação de uma intervenção criativa do tradutor.

Segundo Haroldo de Campos e a Teoria da Transcriação, o trabalho do tradutor com os signos consiste em "reconhecê-los com sua mirada aléfica e, através deles, redesenhar a forma semiótica dispersa, disseminando-a, por sua vez, no espaço da sua própria língua” (Campos 1981: 189). Veremos que em Blow Up, Antonioni altera características periféricas na tradução icônica de tipo paramórfica - mantém o modelo discursivo alterando a estrutura narrativa -, e a partir disso discutiremos qual efeito sobre o signo tem esse processo de transcriação.

Sem nos determos no campo conceitual da semiótica, voltar-nos-emos à função do sistema teórico intersemiótico na relação entre literatura e cinema. Com o auxílio dos estudos sobre literatura e cinema de Tânia Pelegrinni, discutiremos os recursos que viabilizam a bem-sucedida tradução, por critérios intersemióticos, do conto cortazariano para o filme de Antonioni.

\section{Blow Up e "Las babas del diablo"}

Antonioni optou pelo processo de transcriação ao trabalhar com a inspiração fornecida pelo conto cortazariano, ao invés da transposição direta, mantendo assim informações estéticas essenciais que provavelmente se perderiam no deslocamento de significantes, pelo fato de a linguagem fílmica ser notoriamente distinta da linguagem literária. Entretanto, de acordo com os estudos sobre adaptação fílmica, há mais recursos 
aproximadores entre a literatura e o cinema do que geralmente se discute. Especialmente os métodos narrativos são material interessante para se pensar essa interação entre artes. "Pode-se nesse sentido, perceber uma conexão muitas vezes às claras, outras vezes apenas sugeridas entre textos ficcionais e as linguagens visuais" (Pellegrini 2003: 16).

Assim, selecionamos as cenas e os trechos da narrativa ligados à construção do personagem central e sua configuração temática sistematizados nas cenas em que a) há captura da fotografia; b) é feita a revelação da imagem; c) ocorre a tomada de consciência do crime por parte do personagem principal; para refletirmos como a obra de Antonioni demonstra a operacionalização do processo de tradução intersemiótica em Blow Up. 0 que trabalhamos no conto através da análise textual, no filme pode ser verificado através de técnicas narrativas próprias da linguagem cinematográfica.

(...) o meio usado para dar vida ao espaço é a descrição, que pode, pela sucessão discursiva, representar objetos simultâneos e justapostos. É principalmente com a descrição (já usada para mimetizar a pintura e a fotografia) que os recursos cinematográficos podem ser transpostos para as técnicas narrativas: o narrador pode usar "a panorâmica, o traveling, a profundeza do campo, os jogos de luz, a distância em relação ao objeto e a mudança de planos para situar a personagem", além de, com esses mesmos recursos, podem interferir no fluxo da ação e no envolver do tempo. (Pellegrini 2003: 26)

No instante em que o personagem Thomas resolve ir ao parque para fotografar, temos o enquadramento do Plano Geral, destacando a interação espaço e ação, isto é, o fazer do fotógrafo. Em seguida, também em Plano Geral, o casal surge na paisagem escondendose entre as árvores do parque. Ao vê-los, Thomas demonstra entusiasmo numa postura cômica de saltitar sorrateiramente atrás do casal. Uma perspectiva panorâmica simula a visão focal da câmera de Thomas, que mira o casal. A mulher mostra-se insegura gesticulando nervosamente e, ao perceber que está sendo fotografada, vai em direção a Thomas. Ao estabelecerem diálogo numa escadaria, Thomas fica em degraus mais altos, num enquadramento Contra-Plongée que acentua o efeito de superioridade. Enquanto discutem pela posse do rolo de negativos da câmera, Thomas desdenha as reivindicações da 
mulher afirmando: "Most girls would pay me to photograph them" (A maioria das garotas me pagaria para que as fotografasse). ${ }^{2}$ Após a insistência da mulher, Thomas investe com uma expressão de flerte: “Don't let spoil everything, we've only just met” (Não estrague tudo, acabamos de nos conhecer).

Pode-se verificar no conto que as duas falas implicam figuras que caracterizam o personagem principal, isto é, sedutor e arrogante, características indicadoras de contiguidade nas cenas de Antonioni. Quando no conto Michel dialoga com a mulher que considera bela ("Era delgada y esbelta, dos palabras injustas para decir lo que era"), ${ }^{3}$ insinua o flerte através da afirmação: "Por mi parte se me importaba muy poco darle o no el rollo de película, pero cualquiera que me conozca sabe que las cosas hay que pedírmelas por las buenas" (p. 89).4 0 desdém de Michel, assim como o de Thomas, é marcadamente expresso, e no conto se manifesta através do modo como vai embora sem considerar as reivindicações: "Me les reí en la cara y eché a andar" (p. 90). 5 A importância dessas figuras está ligada à modulação do sujeito ao longo da narrativa, que decai de uma situação de poder para um estado de impotência e assujeitamento.

Nesta mesma cena, há elementos icônicos que são trabalhados por uma intervenção criativa de reescrita na obra de Antonioni. A substituição do adolescente do conto por um homem mais velho no filme fornece desdobramentos que não seriam possíveis na narrativa de partida. No texto original, a presença do adolescente subsidia um espectro de inocência, e o efeito do horror está na ideia da perda de integridade física e psicológica do personagem. Em Antonioni, a trama envereda numa questão mais existencial suscitada pela dicotomia vida e morte, o que altera a estrutura narrativa conforme as traduções icônicas do tipo paramórficas, isto é, traduções que mantém o modelo alterando a estrutura.

Durante o processo de revelação das fotografias, o fechamento em zoom in atende à demanda de atenção às minúcias das imagens. Após a seleção das ampliações feitas por Thomas, o movimento da câmera focaliza as imagens colocando o rosto da mulher no plano detalhe, mostrando o impacto emocional da circunstância. A sequência de fotografias funciona como peças de um quebra-cabeça que se encaixam e resultam na informação da iminência do crime. Quando Thomas percebe que sua interferência como fotógrafo pode ter 
salvo a vida de um homem, sua reação é telefonar para um amigo e tentar, sem sucesso, contar-lhe o que aconteceu. O amigo parece displicente e no fundo Thomas conversa sozinho. A ligação é a solução que Antonioni encontrara para que pudesse falar o que no conto o fotógrafo apenas pensa.

Esta sequência é atravessada pela inserção de duas personagens femininas que figuram uma passagem de teor erótico, na qual há a famosa cena de nudez da jovem Jane Birkin, momento que inexiste no texto cortazariano. 0 enredo volta ao diálogo mais direto com a obra literária, quando Thomas, ao regressar às fotografias, já não está entusiasmado por ter testemunhado um crime, pelo contrário, seu semblante é de preocupação e abatimento. Após uma nova ampliação da última fotografia tirada, Thomas visualiza um corpo estendido no chão. A partir desse momento o jovem e presunçoso fotógrafo mostrase desnorteado ao levar as mãos à cabeça, andar de um lado para o outro, mirar novamente a fotografia e, num efeito de sobrecarga emocional, decide sair de casa abruptamente.

No conto de Julio Cortázar, a tomada de consciência do horror que Michel presenciara culmina num choro desesperado:

Jadeando me quedé frente a ellos; no había necesidad de avanzar más, el juego estaba jugado. (...) un instante aún en perfecto foco y después todo él un bulto que borraba la isla, el árbol, y yo cerré los ojos y no quise mirar más, y me tapé la cara y rompí a llorar como un idiota. (Cortázar 1972: 98$)^{6}$

Em Antonioni o processo de desesperação é gradual, começa com a contemplação das fotografias e segue com a averiguação do local e seu retorno no dia seguinte. Nesse ponto, já é possível marcar a paridade indicial do percurso de modulação do personagem principal. No texto de partida, Cortázar utiliza a palavra "impotência" (p. 84) para descrever o sentimento de Michel. Esta impotência é presente em Blow Up nas ações inúteis de Thomas a partir de sua tomada de consciência. Há, portanto, a tendência ao esgarçamento do sentimento catártico presente no texto literário, para que ao reduzir a tensão pontual haja um prolongamento da angústia que proporciona o alongamento da narrativa e o prosseguimento do filme. 
Em entrevista a Omar Prego Gadea, Cortázar discorre sobre essa tendência que os filmes têm de expandirem as dimensões do conto, ressaltando que, enquanto na adaptação cinematográfica de romances pode haver uma perda de informações significativas pela redução do texto, no conto ocorre o contrário, há um acréscimo, sem com isso determinar como esse acréscimo influi na qualidade do signo.

El cuento, en cambio, precisamente por su naturaleza, porque aunque haya muchas acciones el cuento está concentrado en una sola acción, donde los personajes son generalmente menores en número, se presta más como un posible escenario. Al contrario de lo que te decía para la novela, yo pienso que en manos de un buen adaptador, de un adaptador inteligente y sensible, muchos cuentos incluso alcanzan un mayor desarrollo en el cine. No sé si para o bien o para mal, eso ya sería algo diferente. (Gadea 1984: 284-285) ${ }^{7}$

Esse prolongamento que ocorre através da transcriação do adaptador revela o que Plaza afirma sobre a capacidade da tradução icônica de "aumentar as taxas de informação estética" (Plaza 2008: 93) do texto de chegada. Durante o processo de buscas, Thomas se depara com a completa impossibilidade de ter certeza do crime. Embora haja o registro fotográfico, as ampliações lembram quadros impressionistas cuja distorção de pixels sugere um conjunto de formas indefinidas. Thomas não tem mais certeza do que vê. As fotografias já não fornecem um retrato fiel. Nota-se aqui a retomada do problema da representação como objeto de tematização da narrativa.

O problema da representação se faz presente na obra cortaziana desde o título do conto, afinal "Las babas del diablo" alude ao comentário do narrador sobre os diversos significantes que um mesmo significado pode ter, no caso "os fios da Virgem se chamam também de as babas do diabo" (p. 79). O final de Blow Up endossa a estrutura icônica ao inserir um grupo de personagens mímicos que fingem jogar tênis com bola e instrumentos invisíveis, e ao convidarem Thomas para participar do ilusionismo, este não declina. Um fim emblemático para as discussões sobre os jogos de ilusões da linguagem e da arte. Em Cortázar, o fim do conto segue um movimento cíclico retomando a discussão sobre as dificuldades de narrar tendo como referência o "real" e a "verdade". 
Lo que queda por decir es siempre una nube, dos nubes, o largas horas de cielo perfectamente limpio, rectángulo puríssimo clavado con alfileres en la pared de mi cuarto. Fue lo que vi al abrir los ojos y secármelos con los dedos: el cielo limpio (...). (Cortázar 1972: 96) ${ }^{8}$

Conseguimos verificar que duas das principais figuras que compõem a configuração temática do texto original são mantidas como signos presentes no procedimento de transcriação para o cinema: a) o problema da representação e b) o processo de assujeitamento do personagem principal em decorrência de sua relação com o signo imagético. Assim, vemos que os elementos estruturais de significado mais relevantes na produção fílmica se harmonizam com o texto literário no nível discursivo, embora no nível narrativo haja uma reorganização actancial distinta do conto cortazariano em razão da elaboração que a diegese cinematográfica exige.

\section{Conclusão}

Buscamos através deste trabalho pensar como ocorre o diálogo intersemiótico nas práticas de tradução do texto literário para adaptação fílmica, respeitando as demandas estéticas que cada linguagem apresenta. Ao fazer a aproximação de gêneros narrativos tão distintos, encontram-se intersecções discursivas que tornam viáveis a implementação de técnicas analíticas eficazes na verificação dos signos mais relevantes na construção de sentido.

Vimos que é possível tecer considerações pertinentes ao processo de tradução com base nos recursos que a semiótica de extração pierceana fornece, em cooperação com os estudos críticos do cinema e da literatura. Compreendemos que Antonioni se sentiu motivado a ousar em sua adaptação, e aplicar o procedimento da transcriação, valorizando intensamente a tradução icônica. Isto resultou numa criação fílmica de estética distinta da obra original, sem abrir mão do eixo discursivo que mantém as obras ligadas numa construção de sentido mais profunda.

Com este trabalho colaboramos para os estudos da tradução ligados à adaptação cinematográfica a partir de textos literários, e para uma perspectiva de trabalho e análise mais equânime no trato com linguagens, neste caso literatura e cinema, que comumente são 
tratadas em moldes hierárquicos incoerentes com a real complexidade artística que ambas possuem.

\section{NOTAS}

1 “Nunca se saberá como isto deve ser contado [...]. Vai ser difícil porque ninguém sabe direito quem é que verdadeiramente está contando, se sou eu ou isso que aconteceu, ou o que estou vendo (nuvens, às vezes uma pomba) ou simplesmente como uma verdade que é somente minha verdade, então não é verdade (...)" (CORTÁZAR, Julio. As armas secretas. Tradução de Eric Nepomuceno. Rio de Janeiro: Civilização Brasileira, 2014, pp. 69-70).

${ }^{2}$ Quanto às falas de Thomas, traduções nossas.

${ }^{3}$ CORTÁZAR, Julio. Las armas secretas. Buenos Aires: Editorial Sudamericana, 1972, p. 84. "Esbelta e delgada, duas palavras injustas para dizer o que era" (CORTÁZAR, Julio. As armas secretas. Tradução de Eric Nepomuceno. Rio de Janeiro: Civilização Brasileira, 2014, p. 74).

4 "Por mim tanto fazia dar ou não o rolo do filme, mas qualquer um que me conheça sabe que, comigo, as coisas têm de ser pedidas com jeito" (CORTÁZAR, Julio. As armas secretas, p. 79).

5 "Ri na cara deles e comecei a andar" (idem: 80).

6 "Arfando fiquei na frente deles; não havia necessidade de avançar mais, o jogo estava jogado. (...), um instante ainda em perfeito foco, e depois ele todo um vulto que apagava a ilha, a árvore, e eu fechei os olhos e não quis olhar mais e cobri o rosto e desandei a chorar feito um idiota" (idem: 85-86).

70 conto, por sua vez, precisamente por sua natureza, porque ainda que haja muitas ações no conto, está concentrado em uma só ação, em que os personagens menores em número, se presta mais como um cenário possível. Ao contrario do que te dizia sobre o romance, penso que em mãos de um bom adaptador, um adaptador inteligente e sensível, muitos contos inclusive alcançam um maior desenvolvimento no cinema. Não sei se para o bem ou para o mal, isso já é outro assunto.

8 "O que resta por dizer é sempre uma nuvem, duas nuvens, ou longas horas de céu perfeitamente limpo, retângulo puríssimo cravado com alfinetes na parede do meu quarto. Foi o que vi ao abrir os olhos e secá-los com os dedos: o céu limpo (...)” (CORTÁZAR, Julio. As armas secretas, p. 86). 


\section{Bibliografia}

BLOW UP (1966). Direção: Michelangelo Antonioni, Produção: Carlo Ponti. Londres (UK): Metro Goldwyn Mayer, 1DVD.

Campos, Haroldo de (1994), "Transblanco: Reflexões sobre a transcriação de Blanco, de Octavio Paz, com um excurso sobre a teoria da tradução do poeta mexicano". In: Campos, Haroldo de; Paz, Octavio, Transblanco, 2. ed., São Paulo, Siciliano.

Cortázar, Julio (2014), As Armas Secretas, tradução de Eric Nepomuceno, Rio de Janeiro, Civilização Brasileira.

-- (1972), Las Armas Secretas, 12ํe edición, Buenos Aires, Editorial Sudamericana.

Gadea, Omar Prego e Cortázar, Julio (2004), La Fascinación de las Palabras, Buenos Aires, Alfaguara.

Peirce, C.S. (2010), Semiótica, tradução de José Teixeira Coelho Neto, São Paulo, Perspectiva.

Pellegrini, Tânia et al (2003), Literatura, Cinema e Televisão, São Paulo, Editora Senac/ São Paulo, Instituto Itaú Cultural.

Plaza, Julio (2001), Tradução Intersemiótica, São Paulo, Perspectiva. 
Lia Leite Santos é mestra em Literatura Comparada pelo Programa de Pós-Graduação em Letras da UFC (Universidade Federal do Ceará), licenciada em Letras, Língua Portuguesa e Literaturas, na mesma instituição. Editora da Revista Entrelaces (ISSN: 1980-4571). Integrante do GELTTE (Grupo de Estudos de Literatura, Tradução e suas Teorias). Desenvolveu, sob a orientação da professora Roseli Barros, a dissertação $O$ signo identificante: a dimensão ética no experimentalismo de Julio Cortázar em Rayuela, em que aproxima literatura e filosofia, investigando como os recursos estéticos, especialmente o experimentalismo de matriz surrealista do romance Rayuela (1963), do escritor argentino Julio Cortázar, são fonte de um discurso ético e metafísico no campo literário. 